\title{
Infección respiratoria por metapneumovirus humano en pacientes adultos mayores
}

\author{
Alberto Fica C., Loreto Hernández C., Lorena Porte T., Marcelo Castro S. y Thomas Weitzel
}

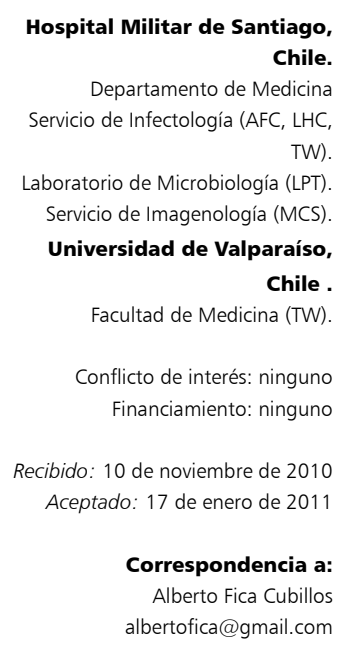

\section{Respiratory infections caused by metapneumovirus in elderly patients}

Human metapneumovirus infections are increasingly recognized among adult patients and the aim of this report is to present a series of 4 cases admitted during the winter of 2010 . All were detected by direct fluorescence antibodies assay of respiratory samples and all were female patients with an age range of 79 to 95 years, including two bedridden cases, one with dementia and three with chronic obstructive pulmonary disease. One patient presented with parainfluenza 3 virus coinfection. Patients presented with pneumonia in 3 cases (interstitial pattern in 2 and lobar consolidation in the other) or acute exacerbation of chronic bronchitis in the remaining case. Symptoms were present for 3 to 7 days before admission and 3 have wheezing. All had hypoxemic or global respiratory failure and lymphopenia $\left(<1.000 / \mathrm{mm}^{3}\right)$. Hospitalization lasted for 5 to 20 days, marked in the 3 cases that survived by prolonged bronchial obstructive manifestations. Two cases required non invasive mechanical ventilation. Human metapneumovirus infections can decompensate elderly patients with chronic respiratory diseases generating hospital admission and a prolonged morbidity marked by obstructive manifestations and sometimes can become into death.

Key words: metapneumovirus, chronic obstructive pulmonary disease, elderly, pneumonia, fluorescent antibody technique, lymphopenia

Palabras clave: metapneumovirus, enfermedad pulmonar obstructiva crónica, neumonía, inmunofluorescencia, adulto, linfopenia

\section{Introducción}

L as infecciones por metapneumovirus humano (MPVH) son ampliamente conocidas y aceptadas en pacientes pediátricos, en quienes han sido ligadas a cuadros respiratorios agudos con bronquiolitis y sibilancias. El agente causal pertenece a la familia Paramoxyviridae, corresponde a un virus ARN y está emparentado con el virus respiratorio sincicial (VRS) y los virus parainfluenza ${ }^{1}$. A pesar de su indiscutido rol patogénico en pacientes pediátricos, el reconocimiento de su importancia en adultos es más limitado y sólo en los últimos años se ha ido delineando con mayor precisión su participación como agente de infecciones virales en diferentes grupos de pacientes y su importancia en hospitalizaciones y brotes.

Comunicamos a continuación una pequeña serie de pacientes adultos hospitalizados a causa de infección por MPVH y comentamos su importancia etiológica en este grupo etario.

\section{Pacientes y Métodos}

Los casos fueron identificados por el registro de exámenes de inmunofluorescencia directa (IFD) para agentes virales respiratorios existente en el laboratorio clínico. Cada caso fue analizado con una pauta estructurada, buscando datos demográficos, factores de riesgo conocidos para infección por este agente, antecedentes mórbidos, cuadro clínico, hallazgos radiológicos y exámenes de laboratorio al ingreso, evolución, tratamientos recibidos y condición al egresar.

La presentación clínica fue catalogada como neumonía o bronquitis crónica reagudizada según criterios preestablecidos ${ }^{2,3}$.

La duración de la signología obstructiva fue obtenida de los registros en la ficha clínica sin aplicar pruebas espirométricas.

La detección de MPVH fue efectuada mediante IFD con anticuerpos monoclonales (Diagnostic Hybrids, Ohio, USA) desde una muestra respiratoria obtenida por tórula nasofaríngea.

\section{Resultados}

Durante el año 2010 se identificaron cuatro casos de infección respiratoria por MPVH. Los cuatro casos correspondieron a pacientes de sexo femenino, con edad avanzada (rango 79 a 95 años) y fueron observados sólo en los meses de invierno (agosto y septiembre). Ninguno 
estaba institucionalizado pero, al menos dos de ellos, estaban postrados y uno tenía demencia. Tres de ellos presentaban antecedentes de EPOC, en algunos casos por tabaquismo, pero ninguno recibía $\mathrm{O}_{2}$ domiciliario. Dos de los pacientes eran usuarios de corticosteroides por vía inhalatoria (Tabla 1).

La forma de presentación clínica fue neumonía en tres casos y de bronquitis crónica reagudizada en el caso restante, con un tiempo de evolución de tres a siete días antes del ingreso. Todos refirieron fiebre y las sibilancias fueron pesquisadas en tres de los cuatro casos. Las condiciones de ingreso indicaron pacientes con taquipnea, baja saturación de $\mathrm{O}_{2}$ y falla respiratoria global o hipoxémica en todos ellos. El patrón radiológico identificado correspondió a infiltrados intersticiales o consolidación lobar en los tres casos con alteraciones parenquimatosas. En una paciente no se encontró neumonía (Tabla 1).

Una paciente con un vómito aspirativo probablemente tusígeno evolucionó con hipotensión arterial y con parámetros de laboratorio muy alterados, incluyendo una gran leucocitosis neutrofílica y valores elevados de LDH plasmática. Exceptuando este caso, los valores de leucocitos se mantuvieron en rango normal o discretamente alterados. Todos presentaron linfopenia $<1.000 /$ $\mathrm{mm}^{3}$ (Tabla 1).

Aunque no se hizo una búsqueda extensiva y sistematizada, no se identificaron co-infecciones salvo un caso con virus parainfluenza 3 .

Tabla 1. Antecedentes bio-demográficos y características clínicas de 4 casos de infección por metapneumovirus humano

\begin{tabular}{|c|c|c|c|c|}
\hline Parámetro (valor normal) & Caso 1 & Caso 2 & Caso 3 & Caso 4 \\
\hline Edad (años), sexo & 95, fem & 79, fem & 94, fem & 91, fem \\
\hline Mes de hospitalización & Agosto & Agosto & Agosto & Septiembre \\
\hline Postración & No & No & Sí & Sí \\
\hline EPOC & Sí & Sí & No & Sí \\
\hline Tabaquismo previo o actual & Sí & No & No & Sí \\
\hline Corticosteroides inhalatorio o sistémico & No & Si, inhalatorio & No & Si, inhalatorio \\
\hline Otros antecedentes clínicos & $\begin{array}{l}\text { Cardiopatía hipertensiva } \\
\text { Cáncer de mama }\end{array}$ & & $\begin{array}{l}\text { Demencia, accidente vascular } \\
\text { Enfermedad de Parkinson }\end{array}$ & $\begin{array}{l}\text { Artritis reumatoide sin } \\
\text { inmunosupresión }\end{array}$ \\
\hline Cuadro clínico & $\begin{array}{l}\text { Bronquitis crónica reagudi- } \\
\text { zada }\end{array}$ & Neumonía & Neumonía & Neumonía \\
\hline Patrón radiológico & Sin neumonía & $\begin{array}{l}\text { Infiltrado intersticial pulmonar } \\
\text { derecho }\end{array}$ & Infiltrado intersticial bilateral & $\begin{array}{l}\text { Consolidación lóbulo inferior } \\
\text { derecho }\end{array}$ \\
\hline Tiempo evolución (días) & 3 & 7 & 7 & 7 \\
\hline Sibilancias & No & Sí & Sí & Sí \\
\hline Fiebre & Sí & Sí & Sí & Sí \\
\hline Frecuencia respiratoria ( $\mathrm{N}:<20 / \mathrm{min}$ ) & $30 / \mathrm{min}$ & $44 / \mathrm{min}$ & $33 / \mathrm{min}$ & $27 / \mathrm{min}$ \\
\hline Saturación $\mathrm{O}_{2}$ (aire ambiental) & $82 \%$ & $77 \%$ & $88 \%$ & $86 \%$ \\
\hline $\mathrm{PaFiO}_{2}(>400)$ & 253 & 108 & 224 & 219 \\
\hline Tipo de falla respiratoria & Global & Global & Parcial & Global \\
\hline Hipotensión arterial & No & No & Sí & No \\
\hline Hemoglobina (12 a 16 g/dL) & 14,2 & 15,1 & 11,4 & 10,3 \\
\hline Leucocitos $/ \mathrm{mm}^{3}$ (N: 4.000 a 11.000$)$ & 9.400 & 7.600 & 34.600 & 12.100 \\
\hline Linfocitos $/ \mathrm{mm}^{3}(>1.000)$ & 570 & 930 & 850 & 960 \\
\hline $\mathrm{PCR}(<10 \mathrm{mg} / \mathrm{L})$ & 18 & 62,3 & 211 & 128 \\
\hline Otros agentes & $\begin{array}{l}\text { Parainfluenza } 3 \\
\text { No se solicitaron HC }\end{array}$ & $\begin{array}{l}\text { No en la IF viral } \\
\text { HC negativos } \\
\text { Antígenos urinarios negativos } \\
\text { para } L \text {. pneumophila y } S \text {. } \\
\text { pneumoniae }\end{array}$ & $\begin{array}{l}\text { No en la IF viral } \\
\text { HC negativos }\end{array}$ & $\begin{array}{l}\text { No en la IF viral } \\
\text { HC negativos }\end{array}$ \\
\hline
\end{tabular}




\begin{tabular}{|c|c|c|c|c|}
\hline & Caso 1 & Caso 2 & Caso 3 & Caso 4 \\
\hline Lugar de hospitalización & $\begin{array}{l}\text { Sala general por limitación } \\
\text { del esfuerzo terapéutico }\end{array}$ & Unidad intermedia & $\begin{array}{l}\text { Sala general por limitación } \\
\text { del esfuerzo terapéutico }\end{array}$ & Unidad intermedia \\
\hline Ventilación mecánica & No & VMNI & No & VMNI \\
\hline Corticosteroides y vía & No & Si, sistémico e inhalatorio & No & Si, sistémico e inhalatorio \\
\hline Nebulizaciones & $\mathrm{Si}$ & $\mathrm{Si}$ & $\mathrm{Si}$ & $\mathrm{Si}$ \\
\hline Antimicrobianos & Ceftriaxona & Ceftriaxona-levofloxacina & $\begin{array}{l}\text { Ceftriaxona-metronidazol- } \\
\text { levofloxacina }\end{array}$ & Ceftriaxona-levofloxacina \\
\hline Días de hospitalización & 5 & 20 & 17 & 12 \\
\hline Días con signos obstructivos & 0 & 16 & 11 & 6 \\
\hline Condición al alta & Fallecido & Vivo & Vivo & Vivo \\
\hline
\end{tabular}

Evolución. Dos de los cuatro casos debieron ser manejados en salas de cuidados intermedios y en los otros dos casos se evitó este lugar por indicación expresa de limitar el esfuerzo terapéutico (Tabla 2). En los casos manejados en sala intermedia debió aplicarse ventilación mecánica no invasora junto a corticosteroides sistémicos e inhalatorios. Los pacientes estuvieron hospitalizados en un rango de cinco a 17 días. La prolongación de la internación estuvo asociada a la mantención de los signos obstructivos durante la mitad o más del período de hospitalización. Tres pacientes sobrevivieron. En la paciente fallecida, el deceso se debió a una falla respiratoria global y no presentó neumonía.

\section{Discusión}

Las infecciones por MPVH son bien conocidas en el ámbito pediátrico y han sido descritas en Chile en varias ocasiones $^{4-6}$. Sin embargo, no hay evidencias de publicaciones en nuestro medio que involucren pacientes adultos y tal como lo demuestran los resultados, es relevante comunicar las infecciones por este agente como causa de hospitalización en pacientes mayores.

Esta serie demuestra que MPVH puede ocasionar la descompensación de una condición crónica respiratoria, que representa una causa de hospitalización en pacientes ancianos y que en algunos casos puede provocar la muerte. La gravedad de la descompensación en estos casos quedó en evidencia por la necesidad de internación en salas de atención intermedia y por el uso de ventilación mecánica no invasora. Destaca en esta pequeña serie la presencia de una signología obstructiva importante, la que explica una hospitalización y morbilidad prolongada.

Series prospectivas de pacientes ingresados por neumonía adquirida en la comunidad han demostrado la causalidad de MPVH en estos cuadros durante los meses de invierno en pacientes mayores con condiciones cardiopulmonares crónicas, al igual que lo observado en esta serie ${ }^{1,2,7}$. Sin embargo, a diferencia de la evolución hospitalaria benigna reportada en algunos estudios, parte de nuestros pacientes requirieron hospitalización en salas de cuidados intermedios, tuvieron estadías mayores a siete días y al menos uno de ellos falleció, subrayando que nuestro conocimiento de este agente relativamente reciente es aún parcial ${ }^{2,7}$. Al respecto, y corroborando nuestros hallazgos, en otras series, este agente viral ha sido capaz de provocar una hospitalización de la misma extensión, una tasa equivalente de admisión en UCI y una letalidad similar a la observada por VRS o influenza estacional $^{1}$.

En estudios comunitarios, MPVH ha sido ligado a cuadros respiratorios virales inespecíficos, tanto en pacientes adultos sanos $<60$ ó $>60$ años y aquellos con condiciones cardio-respiratorias crónicas. La participación de este agente en cuadros respiratorios adquiridos en la comunidad ha alcanzado a $2-10 \%$ en pacientes adultos de diferentes edades y condiciones ${ }^{1}$. Además, una fracción adicional presenta evidencias de infección asintomática. Metapneumovirus se presenta con un perfil claramente estacional -está presente en los meses de invierno-y constituye un factor de descompensación en pacientes con asma bronquial ${ }^{1,8}$. Estos antecedentes indican que la gravedad de la infección por MPVH está determinada notoriamente por las condiciones del hospedero y por su edad. Es así como el único paciente fallecido de nuestros casos no tuvo neumonía y el deceso ocurrió por falla respiratoria. La duración de los síntomas también está relacionada a los factores del hospedero y la edad del paciente ya que suele seguir un curso breve en individuos jóvenes en contraste con pacientes mayores ${ }^{9}$.

La frecuencia de las infecciones por MPVH ha sido baja entre los pacientes afectados por neumonía adquirida en la comunidad que requieren hospitalización, sin superar, 
en general, el 5 a $8 \%$ de los casos. Datos prospectivos en pacientes de alto riesgo con infección por MPVH indican que cerca de $18 \%$ requiere ser hospitalizado. La frecuencia de co-infección ha sido variable en pacientes hospitalizados o en pacientes ambulatorios, llegando en ocasiones a superar el 20\% de los casos, un rasgo compatible con lo

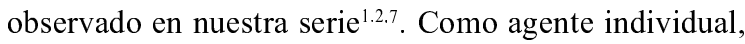
ha ocupado una frecuencia de igual importancia a la observada para el virus influenza y el VRS en pacientes hospitalizados por neumonía adquirida en la comunidad o en pacientes ambulatorios ${ }^{1,2,7}$.

Resaltando su importancia epidemiológica, MPVH ha provocado brotes epidémicos en hogares de pacientes ancianos con una morbilidad significativa, hospitalización $\mathrm{y}$ algunos casos letales ${ }^{9-11}$. También ha sido descrito como causa de neumonía grave en pacientes inmunocomprometidos, en algunos casos con hemorragia pulmonar ${ }^{9}$.

Según Johnstone $\mathrm{J}$ y cols, las infecciones respiratorias causadas por MPVH son, en general, indistinguibles de las presentaciones observadas con otros agentes virales pero pueden ser, en parte, diferenciadas de las de causa bacteriana en pacientes ingresados por neumonía. En bloque, las neumonías virales se presentan a una edad mayor que lo observado con las bacterianas (76 vs 64 años), ocurren en pacientes más dependientes o postrados (48 vs 21\%), se asocian más a pacientes con cardiopatía y presentan una menor frecuencia de dolor torácico (7 vs 37\%). Además, las neumonías virales tienden a presentarse sin leucocitosis (74 vs 14\% en el caso de las bacterianas) y suelen concentrarse en una época específica del año (invierno), a diferencia de las causas bacterianas que pueden observarse todo el año ${ }^{7}$. Como puede apreciarse, notable es la semejanza con lo descrito en este párrafo con la serie de cuatro casos de infecciones presentadas aquí.

Aunque la signología obstructiva respiratoria no es relevante en los pacientes ambulatorios jóvenes, es un hecho muy frecuente en los pacientes que se hospitalizan por esta infección ( $>80 \%$ ). La ausencia de rinorrea, la baja frecuencia de congestión nasal y la presencia de fiebre y bajas saturaciones de oxígeno completan el perfil del paciente hospitalizado por esta causa cuando se compara con pacientes no complicados afectados por este mismo agente ${ }^{1}$.

Uno de nuestros pacientes presentaba antecedentes de artritis reumatoidea sin tratamiento corticoesteroidal, un hecho descrito en la literatura científica y con evolución letal en pacientes con inmunosupresión ${ }^{12}$. Todos los casos en nuestra serie cursaron con linfopenia $<1.000 / \mathrm{mm}^{3}$, un hecho no descrito en las series consultadas. El origen de este fenómeno no pudo ser dilucidado pero puede constituir un rasgo relevante.

El diagnóstico de infección por MPVH puede ser realizado desde muestras respiratorias mediante RT-RPC o inmunoflurescencia directa con anticuerpos monoclonales como en este trabajo. Esta última estratégica está más disponible y tiene una alta sensibilidad y especificidad $(\sim 100 \%)$, comparable a la lograda con RT-RPC ${ }^{13}$. De acuerdo a nuestro conocimiento, esta es la primera vez que se comunica en Chile una serie de casos respaldada por una prueba de inmunofluorescencia y no mediante RT-RPC ${ }^{4-6}$.

Limitaciones. Los pacientes de esta serie no fueron sometidos a un estudio etiológico completo y la posibilidad de co-infección por agentes bacterianos no puede ser descartada por completo. No obstante, en la literatura este fenómeno ha sido infrecuente pese a incorporar varias técnicas de estudio. El diseño de este estudio tampoco permite evaluar la incidencia que tiene esta infección ya que no se puede asegurar si todos los pacientes hospitalizados con cuadros respiratorios en el período fueron sometidos a un estudio etiológico viral.

\section{Conclusiones}

Metapneumovirus puede provocar una infección respiratoria alta o baja en pacientes adultos, es capaz de descompensar a pacientes portadores de condiciones cardiopulmonares crónicas y de edad mayor obligando a su hospitalización. La morbilidad de estos cuadros es prolongada, asociada a la presencia de signología obstructiva respiratoria y en ocasiones puede provocar la muerte del paciente, incluso en ausencia de neumonía. Su diagnóstico se ha facilitado con el advenimiento de una prueba de IFD de alta sensibilidad y especificidad aplicable sobre muestras respiratorias.

\section{Resumen}

Las infecciones por metapneumovirus (MPVH) son poco conocidas en pacientes adultos y el objetivo de esta publicación es presentar una serie de 4 casos observados en pacientes hospitalizados durante el invierno de 2010. Los casos se identificaron por inmunofluorescencia directa en muestras respiratorias. Todos los pacientes fueron de sexo femenino con un rango de edad 79 a 95 años, dos de ellos postrados, uno con demencia y 3 con enfermedad pulmonar obstructiva crónica. La manifestación clínica correspondió a neumonía en 3 casos ( 2 de tipo intersticial y una con consolidación lobar) y bronquitis crónica reagudizada en el caso restante, con una duración sintomática de 3 a 7 días antes de la hospitalización. Un caso presentó co-infección con virus parainfluenza 3. Las sibilancias estuvieron presentes en 3 casos y todos presentaron falla respiratoria hipoxémica o global con linfopenia $\left(<1.000 / \mathrm{mm}^{3}\right)$. La hospitalización tuvo una duración de 
5 a 20 días, marcada en los 3 casos que sobrevivieron por una signología obstructiva prolongada. Dos pacientes requirieron ventilación mecánica no invasora. Las infecciones por MPVH representan una causa de hospitalización por descompensación de patologías respiratorias crónicas en pacientes adultos ancianos, tienen una morbilidad prolongada con signología obstructiva marcada y pueden ocasionar la muerte.

\section{Referencias}

1.- Walsh E E, Peterson D R, Falsey A R. Human metapneumovirus infections in adults. Arch Intern Med 2008; 168; 2489-96.

2.- Johnstone J, Majumdar S R, Fox J D, Marrie T J. Human metapneumovirus pneumonia in adults: results of a prospective study. Clin Infect Dis 2008; 46: 571-4.

3.- Global strategy for the diagnosis, management and prevention of COPD, Global Initiative for Chronic Obstructive Lung Disease (GOLD) 2009. http://www.goldcopd.org. (accedido: noviembre de 2010).

4.- Lozano C, Yáñez L, Lapadula M Lafourcade M, Burgos F, Herrada F, et al. Infección por metapneumovirus humano en niños hospitalizados por una enfermedad respiratoria aguda grave: descripción clínicoepidemiológica. Rev Chil Enferm Respir 2009; 25: 211-17.

5.- Prado A, Perret C, Montecinos L, Veloz A,
Le Corre N, Habash L, et al. Metapneumovirus humano como causa de hospitalización en niños bajo 3 años de edad, con infección respiratoria aguda, durante el año 2004. Rev Chil Infect 2007; 24:19-26.

6.- Luchsinger V, Escobar C, Avendaño LF. Detección de metapneumovirus humano en niños hospitalizados por infección respiratoria aguda baja en Santiago, Chile. Rev Méd Chile 2005; 133: 1059-64.

7.- Johnstone J, Majumdar S R, Fox J D, Marrie T J. Viral infection in adults hospitalized with community-acquired pneumonia. Prevalence, pathogens and presentation. Chest 2008; 134: 1142-8

8.- Williams J V, Crowe Jr J E, Enríquez R, Minton P, Peebles Jr RS, Hamilton RG, et al. Human metapneumovirus infection plays an etiologic role in acute asthma exacerbations requiring hospitalization in adults. J Infect Dis 2005; 192: 1149-53.

9.- Falsey A R. Human metapneumovirus infection in adults. Pediatr Infect Dis J 2008; 27 : S80-S83.

10.- Boivin G, De Serres G, Hamelin M E, Cote S, Argouin M, Tremblay G, et al. An outbreak of severe respiratory tract infection due to human metapneumovirus in a long-term care facility. Clin Infect Dis 2007; 44: 1152-8.

11.- Louie J K, Schnurr D P, Pan C Y, Kiang D, Carter C, Tougaw S, et al. A summer outbreak of human metapneumovirus infection in a long-term care facility. J Infect Dis 2007; 196: 705-8.

12.- O'Gorman C, McHenry E, Coyle P V. Human metapneumovirus in adults: a short case series. Eur J Clin Microbiol Infect Dis 2006; 25: 190-2.

13.- Manoha C, Bour J B, Pitoiset C, Darniot M, Aho S, Pothier P. Rapid and sensitive detection of metapneumovirus in clinical specimens by indirect fluorescence assay using a monoclonal antibody. J Med Virol 2008; 80: 154-8. 